\title{
KANTIN POLITEKNIK DILIHAT DARI PERILAKU MAHASISWA ADMINISTRASI NIAGA SEBAGAI KONSUMEN (Studi Kasus Pada mahasiswa Administrasi Niaga Politeknik Negeri Jakarta)
}

\author{
Azwar $^{1)}$ dan Anwar Mustofa') \\ 1,2 Jurusan Administrasi Niaga, Program Studi Administrasi Bisnis Terapan, \\ Politeknik Negeri Jakarta \\ E-mail:1azwar.pnj@gmail.com, 2anwarmustofa64@yahoo.com
}

\begin{abstract}
This study aims to determine the opinions of bussines Administration students about the Jakarta State Polytechnic canteen, both the kantin bawah (kawah) and the kantin teknik (kantek). Canteen is one of the places of interest by students to meet their physical needs. In relation to fulfilling the needs of these business Administration students, what can be served in the kantin bawah or the kantin teknik is what they need and can not be what they expect either the food offered or the drinks served or other factors they get in canteen. The data analysis method used is qualitative and quantitative analysis or combination analysis. Qualitative is done by describing the results of quantitative analysis, while quantitative analysis using the formula of the attitude indeks. Data collection uses questionnaires given to respondents to obtain primary data and literature studies to obtain secondary data. The results of this study indicate that the biggest attitude index is the technical canteen which is 3.08 and for the lower canteen is 2.73. This reflects that the canteen most favored by business administration students of the Jakarta State Polytechnic is a kantin teknik.
\end{abstract}

Keywords: Canteen, Attitude Index, Consumer Behavior

\begin{abstract}
Abstrak
Penelitian ini bertujuan untuk mengetahui pendapat mahasiswa Adminstrasi Niaga tentang kantin Politeknik Negeri Jakarta, baik kantin bawah (kawah) maupun kantin teknik (kantek). Kantin merupakan salah satu tempat yang diminati dari oleh mahasiswa untuk memenuhi kebutuhan fisiknya. Dalam kaitannya dengan pemenuhan kebutuhan mahasiswa Administrasi Niaga ini bisa saja apa yang disajikan di kantin bawah maupun kantin teknik sesuai dengan yang mereka butuhkan dan bisa juga belum sesuai yang mereka harapkan baik makanan yang ditawarkan maupun minuman yang disajikan atau faktor-faktor lainnya yang mereka dapatkan di kantin. Metode analisis data yang digunakan adalah analisis kualitiatif dan kuantitatif atau analisis kombinasi. Kualitatif dilakukan dengan menjabarkan hasil analisis kuantitatif, sedangkan analisis kuantitatif dengan menggunakan rumus indeks sikap. Pengumpulan data menggunakan kuesioner yang diberikan kepada responden untuk memperoleh data primer dan studi kepustakaan untuk memperoleh data sekunder. Hasil dari penelitian ini menunjukkan bahwa indeks sikap terbesar adalah kantin teknik yaitu sebesar 3,08 dan untuk kantin bawah sebesar 2,73. Hal ini mencerminkan bahwa kantin yang paling disukai mahasiswa administrasi niaga Politeknik Negeri Jakarta adalah kantin teknik.
\end{abstract}

Kata kunci: Kantin, Indeks Sikap, Perilaku Konsumen 


\section{PENDAHULUAN}

\section{Latar Belakang}

Politeknik Negeri Jakarta (PNJ) merupakan lembaga pendidikan tinggi Diploma III yang didirikan untuk memenuhi kebutuhan SDM profesional di industri, baik industri jasa maupun industri manufaktur.

Untuk program studinya sendiri, pada saat ini Politeknik Negeri Jakarta telah menyelenggarakan program pendidikan mulai dari jenjang diploma tiga dan empat. Terdapat 7 konsentasi jurusan yang terdapat di Politeknik Negeri Jakarta, salah satu jurusannya yaitu jurusan Administrasi Niaga.

Orang-orang yang datang ke Politeknik negeri Jakarta bisa sebagai dosen, sebagai karyawan dan juga sebagai mahasiswa. Mahasiswa yang datang ke Politeknik Negeri Jakarta terdapat juga yang mengikuti pendidikan di jurusan Administrasi Niaga.

Kebutuhan akan makanan dan minuman adalah kebutuhan yang tidak dapat dipenuhi dari dalam kelas tetapi kebutuhan yang hanya bisa dipenuhi dari tempat yang bisa menyediakan makanan dan minuman. Politeknik negeri Jakarta mempunyai beberapa fasilitas salah satunya adalah kantin.

Kantin berbeda dengan tempat penyedia makanan lainnya seperti warung nasi, restoran dan cafe. Makanan yang disediakan oleh kantin harganya relatif murah dan terjangkau oleh mahasiswa. Di Politeknik Negeri Jakarta memiliki dua kantin yaitu Kantin Bawah ("Kawah") dan Kantin Teknik ("Kantek"). Kantin bawah ("Kawah") adalah kantin yang terdapat disebelah barat gedung Bank mini dan disebelah selatan dari gedung $\mathrm{H}$ Administrasi Niaga, sedangkan Kantin Teknik ("Kantek") adalah kantin yang terdapat digedung A dan berada di lingkungan Teknik, oleh karena itu disebut dengan Kantin Teknik.

Kantin merupakan salah satu tempat yang diminati dari oleh mahasiswa. Kantin Bawah dan Kantin teknik yang berada dilingkungan Politeknik Negeri Jakarta adalah tempat bagi mahasiswa Administrasi Niaga untuk memenuhi makan dan minumnya disaat mereka lapar dan haus.

Dalam kaitannya dengan pemenuhan kebutuhan mahasiswa Administrasi Niaga ini bisa saja apa yang disajikan di Kantin Bawah maupun Kantin Teknik sesuai dengan yang mereka butuhkan dan bisa juga belum sesuai yang mereka harapkan baik makanan yang ditawarkan maupun minuman yang disajikan atau faktorfaktor lainnya yang mereka dapatkan di kantin Politeknik ini.

Oleh karena itu dalam penelitian ini akan diteliti sikap mahasiswa Administrasi Niaga tentang pendapat mereka mengenai kantin Bawah dan kantin Teknik dengan judul "Kantin Politeknik Dilihat Dari Perilaku Mahasiswa Administrasi Niaga Sebagai Konsumen (Studi Kasus Pada Mahasiswa Administrasi Niaga Politeknik Negeri Jakarta)"

\section{Tujuan}

Berdasarkan uraian mengenai kajian yang akan dibahas, maka tujuan penelitian ini adalah:

a. Untuk mengetahui pendapat mahasiswa tentang kantin politeknik negeri Jakarta, baik kantin bawah ("Kawah") maupun kantin teknik ("Kantek").

b. Untuk mengetahui berapa Indeks sikap terhadap kantin bawah ("Kawah”) dan kantin teknik ("Kantek").

c. Untuk mengetahui kantin mana yang lebih disukai oleh mahasiswa Jurusan Administrasi Niaga, apakah Kantin bawah ("Kawah") atau kantin teknik ("Kantek").

\section{Permasalahan}

Rumusan masalah pada penelitian ini adalah sebagai berikut:

a. Apa faktor yang paling mempengaruhi keputusan pembelian 
pada kantin politeknik negeri Jakarta, baik kantin bawah ("Kawah") maupun kantin teknik ("Kantek”)?

b. Berapa Indeks sikap terhadap kantin bawah ("Kawah") dan kantin teknik (“Kantek")?

c. Mana yang lebih disukai oleh mahasiswa jurusan Administrasi Niaga, apakah Kantin bawah (“Kawah”) atau kantin teknik (“Kantek”)?

\section{Kajian Pustaka}

\section{Overall Quick-casual Restaurant Image}

Menurut Bigne dkk di dalam Nugraha (2013:3) image memiliki sifat yang kompleks dan telah banyak definisi yang telah dikemukakan oleh para ahli yang memiliki wewenang ilmiah untuk mendefinisikan konsep tersebut. Aspek image telah menerima perhatian lebih dalam literatur pemasaran, karena image dapat mempengaruhi subjektifitas persepsi dan perilaku konsekuen seseorang.

\section{Kantin}

Menurut Good (1959) dalam bukunya Dictionary of Education yang dikutip Bella dan Dony (2016:85) mengatakan bahwa:

"cafetaria is a room or building in which public school pupuils or collage student select prepared food and serve themselves".

Kantin adalah suatu ruang atau bangunan yang berada di sekolah maupun perguruan tinggi, di mana menyediakan makanan pilihan/ sehat untuk siswa yang dilayani oleh petugas kantin.

\section{Perilaku Konsumen}

Perilaku konsumen akan mencerminkan sikap dari konsumen dalam melakukan konsumsi. Sikap konsumen akan terlihat dari tanggapan konsumen dalam menikmati dan memenuhi kebutuhannya, tanggapan tersebut akan tercermin dari kepuasan yang didapatkan oleh konsumen.
Menurut Basu Swastha (2017:10) "Perilaku konsumen adalah kegiatankegiatan individu yang secara langsung terlibat dalam mendapatkan dan mempergunakan barang-barang dan jasajasa, termasuk di dalamnya proses pengambilan keputusan pada persiapan dan penentuan kegiatan-kegiatan tersebut”.

Ada dua elemen penting dari arti perilaku konsumen itu:

a. Proses pengambilan keputusan.

b. Kegiatan fisik, yang semua ini melibatkan individu dalam menilai, mendapatkan, dan mempergunakan barang-barang dan jasa-jasa ekonomis.

Mempelajari perilaku konsumen tidak hanya mempelajari apa (what) yang dibeli atau dikonsumsi, tetapi juga di mana (where), bagaimana kebiasaannya (how often), dan dalam kondisi macam apa (under what conditions) barang-barang dan jasa-jasa dibeli tersebut. Untuk dapat melihat dan menggambarkan seorang konsumen berperilaku dapat dilihat dari bahasan-bahasan berikut ini:

1) Konsumen Akhir dan Pembeli Individual

Konsumen akhir adalah individu yang melakukan pembelian untuk memenuhi kebutuhan pribadinya atau konsumsi rumah tangganya. Perbedaan dasar antara konsumen akhir dengan pembeli industri atau pedagang perantara atau lembagalembaga, bahwa perilaku pembelian industri mempunyai motif yang berbeda dan sangat dipengaruhi oleh banyak serta macam individu yang berperan didalamnya.

Menurut Basu Swastha (2017:12) pembeli indivudual adalah seseorang yang melakukan pembelian tanpa atau sedikit sekali dipengaruhi oleh orang lain secara langsung, atau individu yang benar-benar melakukan pembelian. Ini bukan berarti bahwa orang lain tidak terlibat dalam proses terjadinya pembelian, bagaimanapun 
juga banyak orang kan terlibat dalam pengambilan keputusan untuk membeli.

Dalam tabel berikut dapat kita lihat bermacam-macam peran yang terjadi dalam perilaku konsumen.

Di dalam proses terjadinya pembelian terdapat peranan-peranan. Diantara pranan-peranan dalam pembelian tersebut, yang terpenting adalah peranan ketiga. Karena itu, perusahaan dapat meneliti siapa dalam keluarga yang memutuskan sesuatu pembelian, untuk kemudian mengarahkan promosi kepada anggota keluarga itu.

2) Pembelian Sebagai Suatu Proses

Suatu kegiatan pembelian yang nyata hanyalah merupakan salah satu tahap dari keseluruhan proses mental dan kegiatan-kegiatan fisik lainnya yang terjadi dalam proses pembelian pada suatu periode waktu tertentu serta pemenuhan kebutuhan tertentu. Bagian proses lainnya yang mempersiapkan dan mengikuti pembelian nyata tersebut amatlah penting dipahami. Analisa suatu proses pembelian merupakan suatu rangkaian tahapan yang diambil oleh seseorang konsumen. Tahap-tahap dalam proses kegiatan suatu pembelian, digambarkan oleh Philip Kotler dan model pembanding dari Engel, Kollat dan Blackwell seperti tergambar di bawah ini.

Gambar 1. Tahap-tahap Dalam proses Pembelian

(Kotler)

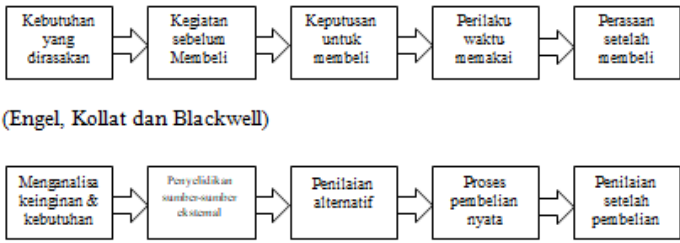

Sumber: Basu Swastha (2017:14), Manajemen Pemasaran, Analisa Perilaku Konsumen.

Banyak peranan atau faktor yang mempengaruhi pada tiap tahap dalam proses pembelian, baik faktor ekstern maupun intern. Perusahaan harus memahami apa yang terjadi dalam tiap tahap dari proses pembelian, sehingga dapat menyusun kegiatan pemasarannya atas dasar tahap-tahap tersebut: jadi bila ingin realistis dalam menganalisa perilaku konsumen, maka harus dipelajari lingkungan sosial, psikologis dan lembaga-lembaga lain yang mempengaruhi dan membatasi tahap perilaku konsumen dalam proses pembeliannya.

Sikap

Menurut Swastha dan Handoko (2017:93)

"Sikap adalah predisposisi (keadaan mudah terpengaruh) untuk memberikan tanggapan terhadap rangsangan lingkungan, yang dapat memulai atau membimbing tingkah laku orang tersebut".

Sikap biasanya memberikan penilaian (menerima atau menolak) terhadap obyek atau produk yang dihadapinya.

Sikap ini dilakukan konsumen berdasarkan pandangannya terhadap produk dan proses belajar baik dari pengalaman ataupun dari yang lain. Dengan memperlajari keadaan jiwa dan keadaan pikir dari sikap seseorang diharapkan dapat menentukan perilaku seseorang.

\section{Konsep Kepuasan (Satisfaction) Konsumen}

Menurut Sudaryono (2014:48) kepuasan adalah "hasil dari penilaian konsumen bahwa produk atau jasa pelayanan telah memberikan tingkat kenikmatan dimana tingkat pemenuhan ini bisa lebih atau kurang”.

Teori kepuasan (the expectancy disconfirmation model) adalah model yang menjelaskan proses terbentuknya kepuasan atau ketidakpuasan konsumen, yaitu merupakan dampak perbandingan antara harapan konsumen sebelum pembelian atau konsumsi dengan kinerja 
sesungguhnya yang diperoleh oleh konsumen. Hasil perbandingan tersebut dapat dikelompokkan menjadi disconfirmation dan confirmation. Secara rinci hasil dampak perbandingan meliputi:

a. Postive disconfirmation, terjadi jika kinerja sesungguhnya (actual performance) lebih besar daripada harapan (performance expectation).

b. Simple confirmation terjadi bila kinerja sesungguhnya sama dengan harapan konsumen,

c. Negative disconfirmation, terjadi apabila kinerja sesungguhnya lebih kecil daripada harapan konsumen.

\section{METODE PENELITIAN}

Metode penelitian yang digunakan penulis adalah metode survei. Tujuan penelitian survei adalah untuk memberikan gambaran secara mendetail tentang latar belakang, sifat-sifat, serta karakter-karakter yang khas dari kasus atau kejadian suatu hal yang bersifat umum.

Data yang diperoleh kemudian diolah, dianalisis dan diproses lebih lanjut dengan dasar-dasar teori yang telah dipelajari untuk menarik kesimpulan sedangkan analisis dilakukan melalui dua pendekatan yaitu kualitatif dan kuantitatif atau kombinasi.

\section{Populasi dan Sampel}

Dalam penelitian ini penulis mendefinisikan populasi didalam penelitian ini adalah mahasiswa Politeknik Negeri Jakarta jurusan Administrasi Niaga yang pernah makan di kantin bawah (Kawah) dan kantin teknik (kantek). Pemilihan teknik sampling dalam penelitian ini adalah metode pengambilan sampel sampling purposive. Untuk mengetahui jumlah sampel yang digunakan maka penulis menggunakan teknik sampling kuota. berdasarkan pendapat tersebut maka peneliti menentukan jumlah sampel sebanyak 50 orang. Dalam penyebaran kuesioner peneliti menggunakan metode sampling insidental.

\section{Teknik Pengumpulan Data}

Adapun metode pengumpulan data yang digunakan penulis sebagai berikut:

a. Data primer

Penelitian Lapangan, yaitu pengumpulan data dengan cara mencari langsung dilapangan. Adapun caranya yaitu dengan Observasi dan Kuesioner.

b. Data sekunder

Studi Kepustakaan, dalam proses penelitian ini dilaksanakan untuk memperoleh data sekunder.

\section{Teknik Pengolahan Data}

Pengolahan data dilakukan untuk mengetahui informasi atau hasil yang diperoleh setelah dilakukan kegiatan pengumpulan data atau pengumpulan informasi dengan tujuan untuk menarik kesimpulan dari banyaknya data yang sudah terkumpul. Kegiatan pengolahan data ini meliputi beberapa tahapan yaitu editting (pengeditan) dan Tabulasi.

\section{Teknik Analisis Data}

Analisa indeks sikap ini digunakan untuk menganalisis sikap dilihat dari perilaku mahasiswa politeknik negeri Jakarta sebagai konsumen. Indeks sikap dirumuskan sebagai berikut:

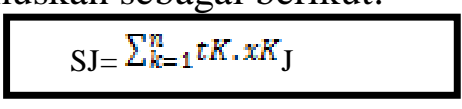

Keterangan:

SJ = Indeks sikap

$\mathrm{tK}=$ timbangan pada atribut $\mathrm{k}$ dari $\mathrm{tK}=1$

$\mathrm{xKJ}=$ nilai atribut untuk merek $\mathrm{j}$

$\mathrm{n} \quad=$ jumlah atribut

(Basu swastha dan T. Hani Handoko, 2017:95)

\section{HASIL DAN PEMBAHASAN Hasil Penelitian}

Berdasarkan kuesioner yang telah disebarkan kepada 50 responden pada tanggal 23-27 Juli 2018, dengan 
respondennya adalah mahasiswa Administrasi Niaga Politeknik Negeri Jakarta, terdiri dari dua objek penelitian yaitu kantin bawah dan kantin teknik, maka didapatkan hasil sebagai berikut.

\section{Kunjungan ke kantin bawah}

Dilihat dari frekuensi kunjungan ke kantin bawah , terdapat 1 responden (2\%) yang menyatakan selalu, 29 responden (58\%) yang menyatakan sering, 20 responden (40\%) menyatakan kadangkadang, dan tidak ada responden yang menyatakan tidak pernah. Untuk lebih jelasnya dapat dilihat pada tabel 4.6. Hal ini mencerminkan bahwa mahasiswa Administrasi Niaga lebih sering datang ke kantin bawah.

Tabel 4.7

Kunjungan ke Kantin Telnuik

\begin{tabular}{|l|r|r|}
\hline Keterangan & Freluensi & Presentase \\
\hline Selalu & 0 & $0 \%$ \\
\hline Sering & 17 & $34 \%$ \\
\hline Kadang-ladang & 33 & $66 \%$ \\
\hline Tidak pemah & 0 & $0 \%$ \\
\hline Total & 50 & $100 \%$ \\
\hline Sumber. Data primer diolah, 2018
\end{tabular}

\section{Kunjungan ke Kantin Teknik}

Dilihat dari frekuensi kunjungan ke kantin teknik , terdapat 17 responden (34\%) yang menyatakan sering, 33 responden (66\%) yang menyatakan kadang-kadang, tidak ada responden yang menyatakan selalu dan tidak pernah. Untuk lebih jelasnya dapat dilihat pada tabel 4.7. Hal ini mencerminkan bahwa mahasiswa Administrasi Niaga kadangkadang datang ke kantin teknik.

Tabel 4.7
Kunjungan ke Kantin Teknik
\begin{tabular}{|l|r|r|}
\hline Keterangan & Frekuensi & Presentase \\
\hline Selalu & 0 & $0 \%$ \\
\hline Sering & 17 & $34 \%$ \\
\hline Kadang-kadang & 33 & $66 \%$ \\
\hline Tidak pernah & 0 & $0 \%$ \\
\hline Total & 50 & $100 \%$ \\
\hline
\end{tabular} Sumber: Data primer diolah, 2018

\section{Rekapitulasi Hasil Penelitian Kantin Bawah}

Untuk mengetahui indek sikap terhadap kantin bawah dilakukan rekapitulasi terhadap objek penelitian tersebut berdasarkan tujuh variabel. Seluruh data responden mahasiswa Administrasi Niaga Politeknik Negeri Jakarta sebagai hasil penelitian ditabulasi pada rekapitulasi yang terdapat pada tabel 4.1 dengan keterangan sebagai berikut:

$\mathrm{A}=$ Harga

$\mathrm{B}=$ Cita rasa

$\mathrm{C}=$ Variasi makanan

$\mathrm{E}=$ Kebersihan Lingkungan

$\mathrm{F}=$ Pelayanan

$\mathrm{G}=$ Tempat yang memadai

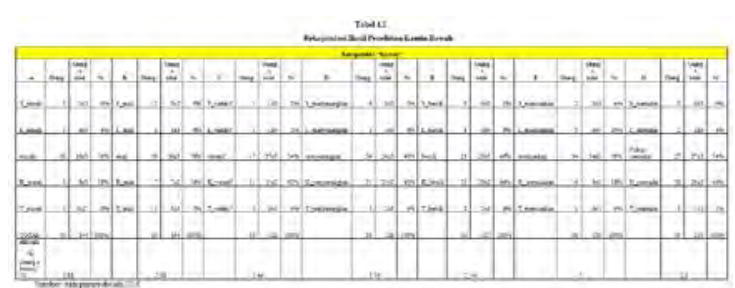

Dilihat dari tabel 4.1 hasil kantin bawah dari faktor harga, sebesar $76 \%$ responden menyatakan murah. Berdasarkan faktor cita rasa sebesar 78\% menyatakan enak. Berdasarkan faktor variasi makanan sebanyak 62\% menyatakan kurang variatif, berdasarkan faktor suasana sebanyak 48\% menyatakan menyenangkan. Berdasarkan faktor kebersihan lingkungan sebanyak 46\% menyatakan bersih. Berdasarkan faktor pelayanan sebanyak 68\% menyatakan memuaskan dan berdasarkan faktor tempat yang memadai sebanyak 54\% menyatakan cukup memadai.

\section{Rekapitulasi Hasil Penelitian Kantin Teknik}

Untuk mengetahui indek sikap terhadap kantin teknik dilakukan rekapitulasi terhadap objek penelitian tersebut berdasarkan tujuh variabel. Seluruh data responden mahasiswa Administrasi Niaga Politeknik Negeri Jakarta sebagai hasil penelitian ditabulasi pada rekapitulasi yang terdapat pada tabel 4.2 dengan keterangan sebagai berikut: 
A $=$ Harga

$\mathrm{B}=$ Cita rasa

$\mathrm{C}=$ Variasi makanan

$\mathrm{E}=$ Kebersihan Lingkungan

$\mathrm{F}=$ Pelayanan

$\mathrm{G}=$ Tempat yang memadai

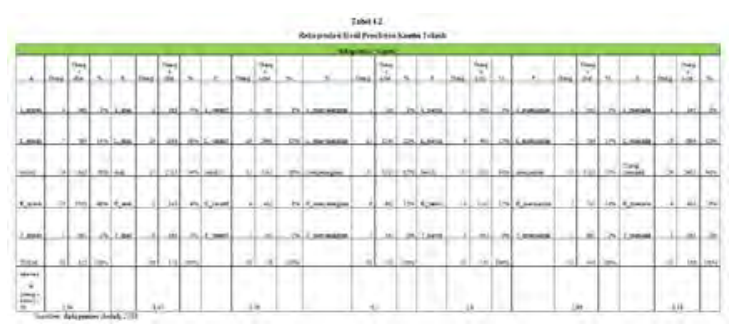

Dilihat dari tabel 4.2 hasil kantin teknik dari faktor harga, sebesar $46 \%$ responden menyatakan murah. Berdasarkan faktor cita rasa sebesar 54\% menyatakan enak. Berdasarkan faktor variasi makanan sebanyak 52\% menyatakan kurang variatif, berdasarkan faktor suasana sebanyak $62 \%$ menyatakan menyenangkan. Berdasarkan faktor kebersihan lingkungan sebanyak 66\% menyatakan bersih. Berdasarkan faktor pelayanan sebanyak $70 \%$ menyatakan memuaskan dan berdasarkan faktor tempat yang memadai sebanyak $48 \%$ menyatakan cukup memadai.

\section{Hasil Nilai Indeks Sikap}

Setelah melakukan rekapitulasi data responden serta menjelaskan dan menjabarkan data perilaku konsumen terhadap tujuh variabel penelitian, telah didapatkan data untuk menghitung indeks sikap. . Maka dari itu untuk mengetahui indeks sikap terhadap kantin bawah dan kantin teknik perlu dicari nilai rata-rata dari masing-masing variabel tersebut. Untuk lebih jelasnya dapat dilihat pada tabel 4.22
Tabel 4.22 Nilai Rata-Rata Variabel

\begin{tabular}{|l|r|r|}
\hline \multirow{2}{*}{ Variabel } & \multicolumn{2}{|c|}{ Nilai rata-rata } \\
\cline { 2 - 3 } & "Kawah" & "Kantek" \\
\hline Harga & 2,88 & 2,64 \\
\hline Cita Rasa & 2,88 & 3,42 \\
\hline Variasi Makanan & 2,44 & 3,56 \\
\hline Suasana & 2,56 & 3,1 \\
\hline $\begin{array}{l}\text { Kebersihan } \\
\text { Lingkungan }\end{array}$ & 2,54 & 2,9 \\
\hline Pelayanan & 3 & 2,96 \\
\hline $\begin{array}{l}\text { Tempat yang } \\
\text { memadai }\end{array}$ & 2,6 & 3,18 \\
\hline \multicolumn{2}{|c|}{ Sumber: Data primer diolah, 2018} \\
\hline
\end{tabular}

Nilai rata-rata variabel tersebut didapatkan dari hasil tanggapan responden terhadap objek penelitian dikalikan dengan bobot nilai kuesioner. Setelah menentukan nilai rata-rata variabel, untuk mencari indeks sikap juga dibutuhkan nilai bobot. Untuk menentukan nilai bobot variabel dapat dilihat pada tabel 4.23.

Tabel 4.23 Nilai Bobot Variabel Penelitian

\begin{tabular}{|c|c|c|}
\hline Keterangan & Orang & $\begin{array}{c}\text { Nilai } \\
\text { Bobot }\end{array}$ \\
\hline Harga & 30 & 0,3 \\
\hline Cita Rasa & 22 & 0,22 \\
\hline Variasi Makanan & 14 & 0,14 \\
\hline Suasana & 8 & 0,08 \\
\hline Kebersihan Lingkungan & 12 & 0,12 \\
\hline Pelayanan & 4 & 0,04 \\
\hline Tempat yang memadai & 10 & 0,1 \\
\hline TOTAL & 100 & 1 \\
\hline
\end{tabular}

Sumber: data primer diolah, 2018

Nilai bobot variabel tersebut didapatkan dari tanggapan konsumen terhadap variabel, konsumen memilih variabel yang paling berpengaruh terhadap objek penelitian. Para konsumen diberi pilihan untuk menentukan prioritas yang paling tinggi pengaruhnya, hingga paling rendah pengaruhnya. Didapatkan harga merupakan variabel yang paling berpengaruh bagi konsumen.

Setelah mendapatkan nilai rata-rata variabel dan nilai bobot variabel, untuk mendapatkan indeks sikap masing-masing objek penelitian yaitu kantin bawah dan 
kantin teknik, penulis mengalikan antara nilai bobot dengan nilai rata-rata variabel yang terdapat pada tabel 4.22 dan 4.23 dan hasil dari perkalian tersebut dapat dilihat sebagai berikut:

a. Indeks sikap terhadap Kantin Bawah Indeks sikap terhadap kantin bawah adalah sebagai berikut:

$=(0,3 \times 2,88)+(0,22 \times 2,88)+(0,14 \times 2,44)+$ $(0,08 \times 2,56)+(0,12 \times 2,54)+(0,04 \times 3)+(0$, $1 \times 2,6)$

$=0,864+0,6336+0,3416+0,2048+$ $0,3048+0,12+0,26$

$=2,73$

b. Indeks sikap terhadap Kantin Teknik Indeks sikap terhadap kantin Teknik adalah sebagai berikut:

$=(0,3 \times 2,64)+(0,22 \times 3,42)+(0,14 \times 3,56)+$ $(0,08 \times 3,1)+(0,12 \times 2,9)+(0,04 \times 2,96)+(0$, $1 \times 3,18)$

$=0,792+0,7524+0,4984+0,248+$

$0,348+0,1184+0,318$

$=3,08$

Semakin besar indeks sikapnya berarti semakin ideal kantin tersebut bagi konsumen. Dari seluruh perhitungan indeks sikap yang ada, diperoleh indeks sikap terbesar adalah kantin teknik ("Kantek") sebesar 3,08, sedangkan untuk kantin bawah ("Kawah”) sebesar 2,73. Hal ini mencerminkan bahwa minat paling tinggi mahasiswa Administrasi Niaga Politeknik Negeri Jakarta yaitu pada kantin teknik (“Kantek”). Dalam hal tersebut, mahasiswa Administrasi Niaga mempunyai sikap yang sangat positif terhadap kantin teknik (“Kantek”).

Setelah mendapat hasil indeks sikap, berdasarkan hasil pembahasan maka didapatkan yaitu indeks sikap "Kawah" 2,73 lebih kecil dari Indeks sikap "Kantek" 3,08.

Uji hipotesis berdasarkan hasil pembahasan maka didapat

Ha : IS "Kawah" 2,73 < IS "Kantek” 3,08

Dari hipotesis tersebut maka hasil hipotesisnya ditolak. Hipotesis tersebut ditolak karena hasil indeks sikap kantin teknik lebih besar dari pada indeks sikap kantin bawah.

\section{KESIMPULAN DAN SARAN \\ Kesimpulan}

Berdasarkan hasil analisis dan pembahasan data, penulis memperoleh kesimpulan yang dapat diambil dari penelitian mengenai Kantin Politeknik Negeri Jakarta Dilihat dari Perilaku Mahasiswa Sebagai Konsumen sebagai berikut:

a. Hasil penelitian menunjukkan bahwa faktor yang paling mempengaruhi keputusan pembelian makanan di kantin bawah dan kantin teknik menurut konsumen adalah harga karena jumlah konsumen yang memlih harga sebanyak 30 orang, kemudian 22 orang memilih cita rasa, 14 orang memilih variasi makanan, 12 orang memilih kebersihan lingkungan, 10 orang memilih tempat yang memadai, 8 orang memilih suasana, dan 4 orang memilih pelayanan. Dilihat dari pendapat konsumen harga pada kedua kantin tersebut sama-sama memiliki harga yang murah, sehingga konsumen bisa memutuskan untuk melakukan pembelian di kantin bawah maupun kantin teknik.

b. Indeks sikap terhadap kantin teknik lebih tinggi dibandingkan dengan indeks sikap kantin bawah di mana indeks sikap kantin teknik sebesar 3,08 dan indeks sikap kantin bawah 2,73.

c. Berdasarkan hasil indeks sikap yang didapat, mahasiswa administrasi niaga lebih menyukai kantin teknik ("Kantek") dari pada kantin bawah ("Kawah") dilihat dari indeks sikap kantin teknik sebesar 3,08 dibandingkan dengan indeks sikap “Kawah” yang hanya 2,73.

\section{Saran}

Berdasarkan data dan pertanyaan terbuka yang penulis berikan di dalam kuesioner kepada responden sebagai acuan, maka penulis mengajukan saran kepada pihak pengelola kantin Politeknik Negeri Jakarta yang diharapkan menjadi masukan yang positif yaitu: 
a. Sebaiknya harga pada kantin bawah dan kantin teknik tetap ditinjau dan terus menyesuaikan daya beli mahasiswa

b. Sebaiknya ruangan kantin diperbesar akan bisa menampung lebih banyak pedagang yang membuat variasi makanannya bertambah banyak.

c. Politeknik Negeri Jakarta sebaiknya lebih memperhatikan kebersihan kantin bawah dan kantin teknik. Apabila mahasiswa telah selesai makan sesegera mungkin meja-meja di kantin dibersihkan dan diperbanyak tempat sampah di kantin bawah maupun di kantin teknik.

d. Politeknik NegeriJakarta sebaiknya memberikan ruang khusus untuk merokok di kantin karena banyak mahasiswa yang mengeluh asap rokok yang membuat tidak nyaman.

e. Sebaiknya kantin bawah dan kantin teknik menambah kipas angin agar suasana tidak panas dan membuat kantin semakin nyaman.

f. Sebaiknya wastafel di kantin diperbanyak dan westafel yang sudah ada diperbaiki dan perlu ditambahkan sabun pencuci tangan.

g. Sebaiknya pelayanan di kantin bawah maupun di kantin teknik diperbaiki seperti kecepatan dalam menyajikan makanan.

\section{DAFTAR PUSTAKA}

\section{Buku:}

Kotler, Philip dan Kevin Lane Keller. 2012. Manajemen Pemasaran Edisi ke-12. Jakarta: Erlangga

Kotler, Philip dan Kevin Lane Keller. 2009. Manajemen Pemasaran Edisi ke-13. Jakarta: Erlangga

Levy, Michael \& Weitz, Barton A. 2012. Retailing Management. New york, Amerika: McGraw-Hill/Irwin

Nababan, H. 2012. Keamanan Pangan di Kantin Sekolah. Jakarta:Direktorat Surveilan dan Penyuluhan Keamanan Pangan Deputi Bidang Pengawasan
Keamanan Pangan dan bahan Berbahaya BPOM RI.

Nitisusastro, Mulyadi. 2012. Perilaku Konsumen dalam perspektif Kewirausahaan. Bandung: Alfabeta

Pasolong, Harbani. 2010. Teori Administrasi Publik. Bandung: Alfabeta.

Sarwono, Jonathan.2011. Mixed Methods Cara Menggabungkan Riset Kuantitatif dan Riset Kualitatif Secara Benar. Jakarta: PT Alex Media Komputindo.

Sedarmayanti. 2009. Sumber Daya Manusia dan Produktivitas Kerja. Bandung: CV Mandar Maju.

Sudaryono.2014.Perilaku Konsumen dalam Perspektif Pemasaran.Jakarta: Lentera ilmu cendekia.

Sugiarto.2017. Metode Penelitian Bisnis.Yogyakarta: ANDI.

Sugiyono.2017. Metode Penelitian Bisnis (Pendekatan Kuantitatif, Kualitatif, Kombinasi, dan R\&D). Bandung: Alfabeta

Swastha, Basu dan Handoko, T. Hani. 2017. Manajemen Pemasaran Analisis Perilaku Konsumen. Yogyakarta: BPFE-Yogyakarta

Swastha, Basu dan Irawan. 2008. Manajemen Pemasaran Modern. Yogyakarta: Liberty

Yulianti dan Hartatik. 2014. Implementasi Pendidikan Karakter di Kantin Kejujuran.Malang: $\quad$ Gunung Samudera 
